OPEN ACCESS

Edited by:

Vasileios Fotopoulos, Cyprus University of Technology,

Cyprus

Reviewed by:

Georgia Ntatsi,

Agricultural University of Athens,

Greece

Costas Delis,

Technological Educational Institute

of Peloponnese, Greece

${ }^{*}$ Correspondence:

Bingru Huang

huang@aesop.rutgers.edu

Specialty section:

This article was submitted to Crop Science and Horticulture, a section of the journal

Frontiers in Plant Science

Received: 21 February 2017

Accepted: 28 June 2017

Published: 11 July 2017

Citation:

Jespersen D, Yu J and Huang $B$

(2017) Metabolic Effects

of Acibenzolar-S-Methyl for Improving

Heat or Drought Stress in Creeping

Bentgrass. Front. Plant Sci. 8:1224.

doi: 10.3389/fpls.2017.01224

\section{Metabolic Effects of Acibenzolar-S-Methyl for Improving Heat or Drought Stress in Creeping Bentgrass}

\author{
David Jespersen ${ }^{1,2}$, Jingjin $Y u^{3}$ and Bingru Huang ${ }^{1 *}$
}

1 Department of Plant Biology and Pathology, Rutgers University, New Brunswick, NJ, United States, ${ }^{2}$ Department of Crop and Soil Sciences, University of Georgia, Griffin, GA, United States, ${ }^{3}$ College of Agro-Grassland Science, Nanjing

Agricultural University, Nanjing, China

Acibenzolar-S-methyl (ASM) is a synthetic functional analog of salicylic acid which can induce systemic acquired resistance in plants, but its effects on abiotic stress tolerance is not well known. The objectives of this study were to examine effects of acibenzolar-Smethyl on heat or drought tolerance in creeping bentgrass (Agrostis stolonifera) and to determine major ASM-responsive metabolites and proteins associated with enhanced abiotic stress tolerance. Creeping bentgrass plants (cv. 'Penncross') were foliarly sprayed with $\mathrm{ASM}$ and were exposed to non-stress $\left(20 / 15^{\circ} \mathrm{C}\right.$ day/night), heat stress $\left(35 / 30^{\circ} \mathrm{C}\right)$, or drought conditions (by withholding irrigation) in controlled-environment growth chambers. Exogenous ASM treatment resulted in improved heat or drought tolerance, as demonstrated by higher overall turf quality, relative water content, and chlorophyll content compared to the untreated control. Western blotting revealed that ASM application resulted in up-regulation of ATP synthase, HSP-20, PR-3, and Rubisco in plants exposed to heat stress, and greater accumulation of dehydrin in plants exposed to drought stress. Metabolite profiling identified a number of amino acids, organic acids, and sugars which were differentially accumulated between ASM treated and untreated plants under heat or drought stress, including aspartic acid, glycine, citric acid, malic acid, and the sugars glucose, and fructose. Our results suggested that ASM was effective in improving heat or drought tolerance in creeping bentgrass, mainly through enhancing protein synthesis and metabolite accumulation involved in osmotic adjustment, energy metabolism, and stress signaling.

Keywords: heat, drought, turf, metabolomics, acibenzolar-S-methyl

\section{INTRODUCTION}

Heat and drought stress are two major abiotic stresses limiting the growth of cool-season perennial grasses. There is increasing use of plant growth regulators (PGRs) in agricultural and horticultural production due to the organic nature and effectiveness of PGRs in promoting plant growth and stress tolerance (Gross and Parthier, 1994; Basra, 2000). However, PGRs vary in their functions of regulating different metabolic processes and in the effectiveness for plant tolerance to different type of stresses (Li et al., 1998; Zhang et al., 2003; Alcázar et al., 2010). Understanding the metabolic 
processes of specific PGRs involved in regulating plant tolerance to heat or drought stress is important for further knowledge of mechanisms or mode of actions of PGRs and the effective and proper use in improving plant stress tolerance.

Acibenzolar-S-methyl (ASM) is an active ingredient in fungicides, which enhances disease resistance by activating the plant's defense system, which is similar to the functions of salicylic acid (Lawton et al., 1996; Cao et al., 2005; Cavalcanti et al., 2006; Deepak et al., 2006, 2007). Salicylic acid has been found to be involved in both biotic and abiotic stress defense due to its role in signaling for the activation of plant immune systems (Durner et al., 1997; Janda et al., 1999; Horváth et al., 2007). A number of metabolic pathways induced by ASM during pathogen attack, including anti-oxidant metabolism, have also been demonstrated to be activated during abiotic stress (Soylu et al., 2003). Several recent studies under field conditions have demonstrated that ASM improved heat and drought tolerance in creeping bentgrass (Shekoofa et al., 2015; Jespersen and Huang, 2016), and the improved drought performance of creeping bentgrass was associated with ASM-reduction of transpirational water loss (Shekoofa et al., 2015). The mode of action for ASM regulation of abiotic stress tolerance is still unclear and how it alters metabolic pathways to improve stress tolerance is not well understood.

One way to explore metabolic changes is through metabolic profiling, which is a powerful way to quantify and identify metabolites involved in important biological functions for plant responses to abiotic stress (Arbona et al., 2013). The accumulation of major stress responsive metabolites including amino acids, organic acids, sugars, and secondary metabolites is an important process for adaptation to abiotic stresses such as heat or drought (Merewitz et al., 2011; Xu et al., 2013). Alterations in these key metabolites demonstrate not only major shifts in metabolism, but also the activation of important defense mechanisms such as anti-oxidant metabolism and osmotic adjustment (Handa et al., 1983; Reddy et al., 2004). Previous research has found that treatment with ASM has led to increased accumulations of polyphenols and anti-oxidants such as ascorbate and glutathione, which may help protect cells during stress events and improve tolerance to pathogens (Iriti et al., 2005; Kuźniak et al., 2014; Meher et al., 2015). Metabolomic studies have also identified changes in amino acids, organic acids, and sugar accumulations in response to treatment with ASM including glucose, malic acid, and sucrose (Dao et al., 2009; Baldoni et al., 2013).

Changing protein accumulation is also a major part of plant responses to abiotic stresses in order to shift metabolism and activate defense pathways (Kosová et al., 2011). This includes alterations to proteins involved in energy metabolism such as ATP synthase, which is involved in generating the ATP needed for metabolic reactions and providing energy needed for stress defense mechanism, or ribulose-1,6-bisphosphate carboxylase oxygenase (Rubisco), a key enzyme in photosynthesis responsible for carbon fixation (Tezara et al., 1999; Feller et al., 2008). Other protein changes are more directly involved in abiotic stress tolerance mechanisms such as heat shock proteins (HSPs) or dehydrins that play protective roles during stress events
(Wang et al., 2004; Hanin et al., 2011). Most changes in protein accumulation due to ASM treatment have been studied in response to pathogen infection and have focused on proteins involved in defense against biotic stresses, finding increased accumulations of pathogenesis related proteins and anti-oxidant proteins such as chitinases, 1,3-betaglucanases, and peroxidases (Burketová et al., 1999; Narusaka et al., 1999; Brisset et al., 2000; Cao and Jiang, 2006). Several proteomic studies have also identified changes to defense proteins such as HSPs, anti-oxidant, and energy proteins, including ATP synthase and Rubisco in response to ASM treatment (Barilli et al., 2012; Gunel et al., 2012; Chen et al., 2015).

The objectives of this study were to determine physiological effects of ASM on heat or drought tolerance in a cool-season perennial grass species, creeping bentgrass and to identify ASM-responsive metabolites which may be responsible for enhanced heat or drought tolerance though metabolic profiling. Furthermore, western blots were used to determine the levels of several key proteins related to abiotic stress tolerance to act as markers to confirm cellular changes in response to ASM treatment.

\section{MATERIALS AND METHODS}

\section{Plant Materials}

Sod plugs of creeping bentgrass (Agostis stolonifera cv. 'Penncross') were collected from mature field plots at Rutgers University turfgrass research farm in North Brunswick, NJ, United States. Plants were transplanted into plastic pots $(10 \mathrm{~cm}$ in diameter, $40 \mathrm{~cm}$ deep) which were filled with a $2: 1(\mathrm{v} / \mathrm{v})$ loamy soil and sand mixture. Plants were watered every other day and fertilized weekly with Hoagland's nutrient solution (Hoagland and Arnon, 1950). Plants were allowed to establish in a greenhouse for 30 days prior to being moved to controlled environment growth chambers (Conviron, Winnipeg, $\mathrm{MB}$, Canada), which were controlled at $20 / 15^{\circ} \mathrm{C}$ (day/night), $14-\mathrm{h}$ photoperiod, and photosynthetically active radiation (PAR) of $600 \mu \mathrm{mol} \mathrm{m}^{-2} \mathrm{~s}^{-1}$.

\section{Chemical and Stress Treatments}

Chemical treatment consisted of ASM applied at a rate of $7.37 \mathrm{mg}$ active ingredient per $\mathrm{m}^{2}$ or a water control. Applications were made as a foliar spray which saturated the canopy with a volume of $3.5 \mathrm{ml}$ per pot. Both ASM solution and the untreated control contained $0.05 \%$ of the surfactant Tween-20. Chemical treatments began 16 days before the imposition of heat or drought stress and continued on a 14 days interval for the duration of the study. The rate and frequency of treatments were based on common use practices of ASM containing products, when being used for disease protection purposes.

The non-stress control plants were maintained well-watered and received $1 / 2$ strength Hoagland's nutrient solution weekly in growth chambers controlled at $20 / 15^{\circ} \mathrm{C}$ (day/night). Drought stress was imposed for plants in growth chambers controlled at $20 / 15^{\circ} \mathrm{C}$ (day/night) by withholding irrigation for 14 days, at 
which point soil volumetric water content had dropped to $6 \%$. For heat stress, plants were well-watered and fertilized in growth chamber controlled at $35 / 30^{\circ} \mathrm{C}$ (day/night) for 56 days.

Each stress treatment was replicated in four pots and placed in four growth chambers. The ASM treatment and untreated control was replicated in four pots. Plants were relocated within and among growth chambers every 7 days to avoid potential confounding effects of environmental variability in different chambers.

\section{Physiological Analysis}

Several commonly used physiological parameters were evaluated to assess stress tolerance. A visual rating of turf quality (TQ) was used to estimate overall plant health and the level of stress damages on a 1-9 scale, with 1 representing dead plants, and 9 representing completely health plants based on canopy color, density, and uniformity (Krans and Morris, 2007). Relative water content (RWC) was used to measure leaf hydration status according to the methods of Barrs (1962). Approximately $0.2 \mathrm{~g}$ of leaf tissue was collected from each pot and immediately the fresh weight was recorded. Leaf tissue was then allowed to become fully turgid by being submerged in de-ionized water for $16 \mathrm{~h}$ and $4^{\circ} \mathrm{C}$, at which point leafs were gently blotted dry with a paper towel and the turgid weight of the rehydrated leafs was recorded. Leaf tissue was then placed in an envelope and dried in an $80^{\circ} \mathrm{C}$ oven for at least $72 \mathrm{~h}$, afterward leaf dry weight was recorded for each sample. RWC was calculated using the equation RWC $=$ (Fresh weight Dry weight)/(Turgid weight - Dry weight $) \times 100 \%$. Chlorophyll content (CHL) was measured to estimate levels of leaf senescence and overall photosynthetic health based on the procedures of Hiscox and Israelstam (1979). Approximately $0.1 \mathrm{~g}$ of fresh leaf tissue was place into $10 \mathrm{ml}$ of dimethyl sulfoxide and allowed to incubate for 5 days in completely darkness to extract pigments from the leaf tissue. The resulting solution was measured using a spectrophotometer (Genesys 2, Spectronic Instruments, Inc., Rochester, NY, United States) at 663 and $645 \mathrm{~nm}$. Leaf tissue was then filtered from the remaining solution and dried in an $80^{\circ} \mathrm{C}$ oven for at least $72 \mathrm{~h}$ to obtain leaf dry weights. Chlorophyll content was calculated on a dry weight basis using the equations described by Arnon (1949). Measurements to assess plant health were performed every 7 days for the duration of the experiments. Additionally, representative leaf tissue samples were harvested at every sampling day and flash frozen in liquid nitrogen and stored at $-80^{\circ} \mathrm{C}$ for further analysis.

\section{Western Blotting Analysis of Protein Expression}

Western blotting was performed to estimate differences in protein levels related to energy metabolism and stress defense induced by stress or chemical treatments. Tissues collected at 56 days of heat stress or 14 days of drought stress, when the greatest physiological differences between treatments was found, were used for western blotting. Proteins were extracted by grinding tissue with liquid nitrogen and then extracting proteins using a tris-LDS extraction buffer. After $30 \mathrm{~min}$ of sonication samples were centrifuges of $5 \mathrm{~min}$ at $10,000 \times \mathrm{g}$. Protein content in the supernatant was quantified using the Bradford assay (Bradford, 1976) and stored at $-80 \mathrm{C}$ for further analysis.

A $20 \mu \mathrm{g}$ of protein per lane was loaded onto a Novex Bis-Tris gel, and run at 200 volts for 30 min using a XCell SureLock MiniCell (Thermo Fisher, Waltham, MA, United States). Proteins were then transferred to a nitrocellulose membrane with a blot module run at 25 volts for $90 \mathrm{~min}$. Membranes were then washed with de-ionized water for $5 \mathrm{~min}$ two times. Membranes were then blocked using a TBS-T buffer which contained $20 \mathrm{mM}$ Tris-Base, $137 \mathrm{mM} \mathrm{NaCl}, 2 \%$ low-fat milk powder, $0.1 \%$ Tween 20 , pH 7.6 by incubating on a shaker for $1 \mathrm{~h}$. The blocking solution was then discarded and membranes were incubated for $16 \mathrm{~h}$ at $4^{\circ} \mathrm{C}$ in an identical TBS-T buffer which contained the desired dilution of the primary antibody. The membrane was then washed in a TBS-T buffer which excluded the blocking agent (milk powder) for $5 \mathrm{~min}$ repeatedly for a total of five washes. The membrane was then incubated for $30 \mathrm{~min}$ in the TBS-T buffer which now contains the desired dilution of the secondary antibody. Following this the membranes were washed with DI water, and the ELC HRP chemiluminesent substrate was used to determine protein levels using a ccd imaging system (Bio-Rad, Hercules, CA, United States). ImageJ was used to quantify relative protein band intensities compared to actin control bands. Proteins quantified include ATP synthase, ribulose-1,5-bisphosphate carboxylase oxygenase (Rubisco), heat shock protein 20 (HSP-20), dehydrin, PR-3, and actin using commercially prepared antibodies (Agrisera, Vännäs, Sweden).

\section{Metabolite Analysis}

Metabolite analysis was performing using gas chromatography mass spectrometry to better understand changes in metabolism caused by environmental or chemical treatments following the procedures but forth by $\mathrm{Du}$ et al. (2011). Leaf tissues collected at 56 days of heat stress or 14 days of drought stress, when the greatest physiological differences between treatments was found, were used for metabolomic analysis. Extraction was performed according to Roessner et al. (2000) with modifications. Frozen samples were first lyophilized (FreeZone 4.5 Labconco, Kansas City, MO, United States) and ground to a fine powder. A total of $25 \mathrm{mg}$ of leaf powder per sample was extracted in $1.4 \mathrm{ml}$ of $80 \%(\mathrm{v} / \mathrm{v})$ aqueous methanol at ambient temperature under $200 \mathrm{rpm}$ for $2 \mathrm{~h}$. Ribitol $(10 \mu \mathrm{l}$ of a $2 \mathrm{mg} \mathrm{ml}^{-1}$ solution) was added to each sample as an internal standard prior to incubation. Samples were then extracted for $15 \mathrm{~min}$ in a $70^{\circ} \mathrm{C}$ water bath, and centrifuged at $12,000 \mathrm{rpm}$ for $30 \mathrm{~min}$. The resulting supernatant were transferred to new tubes and $1.4 \mathrm{ml}$ of water and $0.75 \mathrm{ml}$ of chloroform were added. Samples were thoroughly vortexed, centrifuged for $5 \mathrm{~min}$ at $5,000 \mathrm{rpm}$, and $2 \mathrm{ml}$ of the polar phase (methanol/water) was decanted into $1.5 \mathrm{ml}$ HPLC vials which were then dried in a benchtop centrifugal concentrator (Centrivap Labconco, Kansas City, MO, United States). The dried polar phase was methoximated with $80 \mu \mathrm{l}$ of methoxyamine hydrochloride $\left(20 \mathrm{mg} \mathrm{ml}^{-1}\right)$ at $30^{\circ} \mathrm{C}$ for $90 \mathrm{~min}$ and was trimethylsilylated with $80 \mu \mathrm{l} \quad \mathrm{N}$-Methyl- $N$-trimethylsilyltrifluoroacetamide (with $1 \%$ trimethylchlorosilane) for $60 \mathrm{~min}$ at $70^{\circ} \mathrm{C}$. 
GC-MS analysis followed the procedure described in Qiu et al. (2007). The derivatized extracts were analyzed with a PerkinElmer gas chromatograph coupled with a TurboMassAutosystem XL mass spectrometer (PerkinElmer Inc., United States). Extract aliquots of $1 \mu \mathrm{l}$ were injected into a DB-5MS capillary column $(30 \mathrm{~m} \times 0.25 \mathrm{~mm} \times 0.25 \mu \mathrm{m}$, Agilent $\mathrm{J} \& \mathrm{~W}$ Scientific, Folsom, CA, United States). The inlet temperature was set at $260^{\circ} \mathrm{C}$. After a $6.5 \mathrm{~min}$ solvent delay, initial GC oven temperature was set at $60^{\circ} \mathrm{C} ; 1 \mathrm{~min}$ after injection, the $\mathrm{GC}$ oven temperature was raised $5^{\circ} \mathrm{C} \mathrm{min}^{-1}$, and finally held at $280^{\circ} \mathrm{C}$ for $15 \mathrm{~min}$. The injection temperature was set to $280^{\circ} \mathrm{C}$ and the ion source temperature was set to $200^{\circ} \mathrm{C}$. The helium carrier gas had a constant flow rate of $1 \mathrm{ml} \mathrm{min}{ }^{-1}$. Measurements were made with electron impact ionization $(70 \mathrm{eV})$ in the full scan mode (m/z 30-550). Turbomass 4.1.1 software (PerkinElmer Inc., United States) coupled with commercially available compound libraries (NIST 2005, Wiley 7.0) was used to identify the detected metabolites. For GC/MS results, compounds were identified based on retention times and comparison with reference spectra in mass spectral libraries. Peaks areas of metabolites were integrated with the Genesis algorithm, and relative quantities were calculated using the internal ribitol standard.

\section{Statistical Analysis}

Treatment effects were analyzed using two-way ANOVA and means were separated using Fishers LSD. Additionally, metabolite data was analyzed using principle component analysis (PCA) using JMP Pro (v. 12, SAS Institute Inc., Cary, NC, United States). The heat map was generated using $\mathrm{R}$ (v. 3.4) and the package "heatmap"; representing fold changes from non-stress treatments using a $\log 2$ transformation to assist in visualization of the range of data. MetaboAnalyst (v. 3.0) was used to perform pathway enrichment and topology analysis (Xia and Wishart, 2016). Metabolic pathways with a Holm adjusted p-value of $<0.05$ were considered to be significantly altered by treatment. A Venn diagram comparing metabolites significantly altered by ASM treatment was created using VennPlex (Cai et al., 2013).

\section{RESULTS}

\section{Physiological Improvement of Heat or Drought Tolerance As Affected by ASM}

Under non-stress conditions, no significant differences were found between ASM and untreated control plants for TQ, RWC, or CHL (Figure 1). Under heat or drought stress, TQ, RWC, and CHL were significantly lower in both ASM treated and untreated control plants compared to the non-stress control. Plants treated with ASM maintained significantly higher TQ (7.0), RWC (84.7\%), and CHL (23.2 $\mathrm{mg} \mathrm{g}^{-1} \mathrm{dw}$ ) than those of the untreated control plants with TQ of 4.6, RWC of 57.5\%, and CHL of $15.8 \mathrm{mg} \mathrm{g}^{-1} \mathrm{dw}$ at 56 days of heat stress (Figure 1). During drought stress plants treated with ASM maintained significantly higher TQ (3.7), RWC (24.5\%), and CHL (19.2 $\mathrm{mg} \mathrm{g}^{-1} \mathrm{dw}$ ) compared to untreated control plants with TQ of 2.1, RWC of $18.7 \%$, and $\mathrm{CHL}$ of $15.1 \mathrm{mg} \mathrm{g}^{-1} \mathrm{dw}$, at 14 days drought. These significant physiological differences were only present at the end
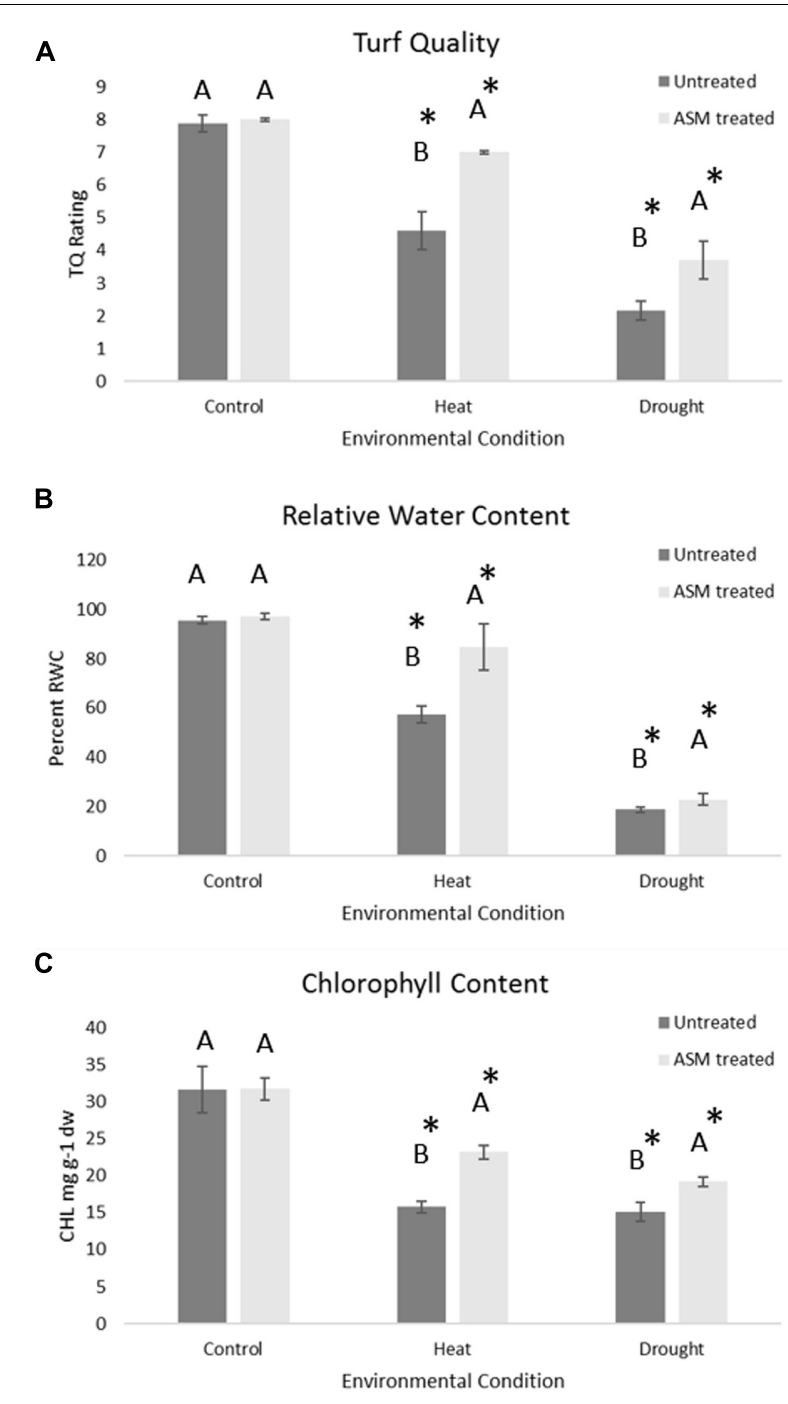

FIGURE 1 | Physiological responses of (A) turf quality, (B) relative water content, and $\mathbf{( C )}$ chlorophyll content in bentgrass under non-stress conditions, 56 days heat stress, or 14 days drought stress when treated with ASM or in untreated controls. Bars represent standard error, letters are LSD groupings, with different letters being significant at $p \leq 0.05$ for treatments in a given environment (control, heat, or drought), while an asterisks $\left(^{*}\right)$ indicates a significant difference for a given treatment when compared to non-stress control conditions.

of heat stress at 56 days, or end of drought stress at 14 days when the greatest amount of stress damages had been accumulated.

\section{Alteration of Protein Expression by ASM under Heat or Drought Stress}

The expression level of selected proteins known to play positive roles in plant tolerance to heat or drought stress was examined in ASM treated and untreated plants to determine whether ASM improved heat or drought tolerance by ASM may be associated with the alteration of the expression of those stress-related proteins. Under control conditions there were no significant differences in the relative protein quantities for ATP synthase, 


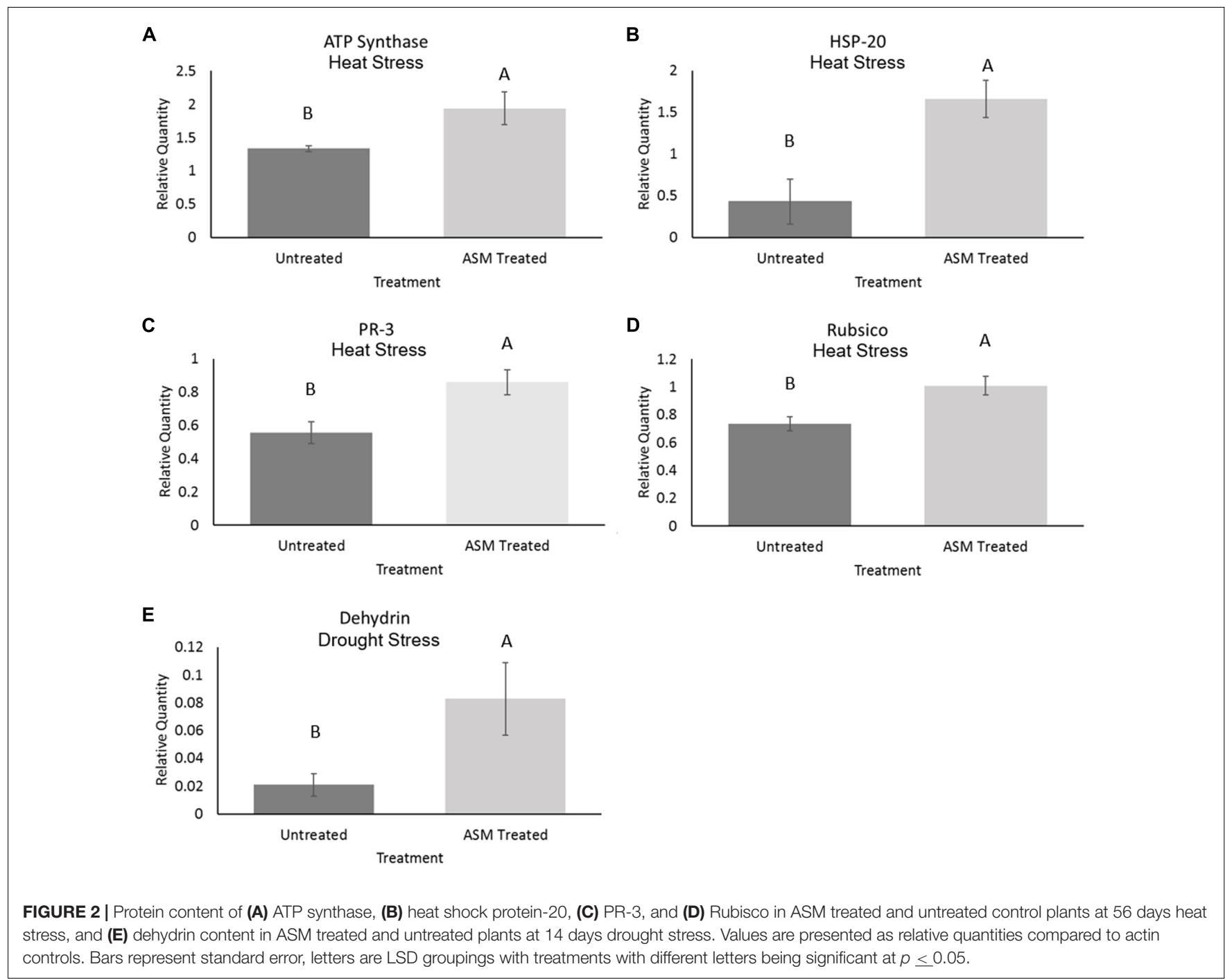

Rubisco, PR-3 or HSP20. Under heat stress conditions ASM treatment resulted in 1.4-fold increases in both the abundance of ATP synthase and Rubisco, 1-5-fold in PR-3 proteins and 3.9-fold in HSP20 compared to the untreated plants (Figure 2). No significant differences were found in dehydrin levels between ASM treated and untreated plants exposed to heat stress. Under drought stress ASM treatment lead to a significant increase in the accumulation of dehydrin with a nearly 5.4 -fold greater protein abundance compared to the untreated control plants (Figure 2). ASM had no significant effects on the expression of other proteins under drought stress.

\section{Alteration of Metabolite Accumulation by ASM under Heat or Drought Stress}

A total of 72 metabolites were identified and quantified using GC/MS, including 22 amino acids, 21 organic acids, 17 sugars, and 12 other metabolites which included sugar alcohols, glycosides, fatty acids, and phytosterols (Table 1). Of the 72 metabolites, 49 metabolites ( 21 amino acids, 10 organic acids, 12 sugars, and 6 other metabolites) showed significantly higher content and 17 metabolites ( 8 organic acids, 4 sugars, and 5 other metabolites) had lower content in heat-stressed plants than the non-stress control plants with or without ASM treatment (Figure 3). Drought-stressed plants had greater contents of 33 metabolites (10 amino acids, 12 organic acids, 9 sugars, and 2 other metabolites) and lower contents of 22 metabolites (5 amino acids, 7 organic acids, 4 sugars, and 6 other metabolites) compared to the non-stress control plants (Supplementary Table S1).

Exogenous applications of ASM resulted in significant changes in metabolite levels during heat or drought stress conditions (Figure 4). The content totals of amino acids significantly increased during heat stress, with untreated plant having a $485 \%$ increase, resulting in significantly higher amino acid totals than ASM treated plants which increased 348\% from non-stress control conditions. Contrastingly, organic acid totals of the measured metabolites decreased in both ASM treated and untreated plants during heat stress. Under heat stress ASM treated plants had significantly more organic acid content than untreated plants, with ASM treated plants' organic acid 
TABLE 1 | Metabolites identified by GC-MS.

\begin{tabular}{|c|c|c|c|}
\hline & Metabolite & $\mathrm{m} / \mathbf{z}$ & $\mathbf{R T}$ \\
\hline 1 & Glycine & 58 & 7.09 \\
\hline 2 & Pyruvic acid & 117 & 8.89 \\
\hline 3 & Acetic acid & 147 & 9.33 \\
\hline 4 & Propenoic acid & 147 & 9.62 \\
\hline 5 & Alanine & 116 & 10.05 \\
\hline 6 & Oxalic acid & 147 & 11.06 \\
\hline 7 & Phosphoric acid & 133 & 12.05 \\
\hline 8 & Valine & 218 & 13.14 \\
\hline 9 & Leucine & 158 & 14.70 \\
\hline 10 & Glycerol & 205 & 14.80 \\
\hline 11 & Isoleucine & 158 & 15.28 \\
\hline 12 & Proline & 143 & 15.36 \\
\hline 13 & Glyceric acid & 189 & 16.28 \\
\hline 14 & Serine & 204 & 17.09 \\
\hline 15 & Threonine & 219 & 17.75 \\
\hline 16 & Maleic acid & 142 & 18.17 \\
\hline 17 & Norvaline & 175 & 18.81 \\
\hline 18 & Homoserine & 218 & 19.39 \\
\hline 19 & Aminomalonic acid & 218 & 19.87 \\
\hline 20 & Malic acid & 147 & 20.38 \\
\hline 21 & Valeric acid & 143 & 20.83 \\
\hline 22 & Methionine & 177 & 21.04 \\
\hline 23 & Aspartic acid & 218 & 21.13 \\
\hline 24 & GABA & 175 & 21.33 \\
\hline 25 & Threonic acid & 205 & 22.10 \\
\hline 26 & Xylulose & 205 & 22.44 \\
\hline 27 & Glutaric acid & 129 & 22.46 \\
\hline 28 & Lyxose & 204 & 23.25 \\
\hline 29 & Glutamic acid & 246 & 23.50 \\
\hline 30 & Asparagine & 116 & 24.63 \\
\hline 31 & Aconitic acid & 147 & 26.41 \\
\hline 32 & Arabinofuranose & 217 & 26.62 \\
\hline 33 & Glutamine & 157 & 26.89 \\
\hline 34 & Shikimic acid & 204 & 27.73 \\
\hline 35 & Glucaric acid & 117 & 27.78 \\
\hline 36 & Citric acid & 273 & 27.85 \\
\hline 37 & Citrulline & 74 & 27.95 \\
\hline 38 & Fructose & 217 & 29.12 \\
\hline 39 & Psicose & 306 & 29.26 \\
\hline 40 & Galactose & 319 & 29.28 \\
\hline 41 & Talose & 205 & 29.42 \\
\hline 42 & Glucose & 205 & 29.77 \\
\hline 43 & Histidine & 155 & 29.80 \\
\hline 44 & Lysine & 175 & 29.93 \\
\hline 45 & Mannitol & 205 & 30.05 \\
\hline 46 & Tyrosine & 218 & 30.22 \\
\hline 47 & Mannobiose & 217 & 30.60 \\
\hline 48 & Arabitol & 103 & 30.95 \\
\hline 49 & Gluconic acid & 205 & 31.24 \\
\hline 50 & Malonic acid & 205 & 31.87 \\
\hline 51 & Inositol & 191 & 31.94 \\
\hline 52 & Myo-inositol & 217 & 33.09 \\
\hline 53 & Glucitol & 205 & 33.51 \\
\hline
\end{tabular}

TABLE 1 | Continued

\begin{tabular}{|c|c|c|c|}
\hline & Metabolite & $\mathrm{m} / \mathbf{z}$ & RT \\
\hline 54 & Tryptophan & 202 & 35.26 \\
\hline 55 & Linolenic acid & 79 & 35.43 \\
\hline 56 & Mannose & 204 & 36.03 \\
\hline 57 & Carotenoic acid & 133 & 36.44 \\
\hline 58 & Glucuronic acid & 217 & 38.11 \\
\hline 59 & Galactofuranoside & 105 & 39.97 \\
\hline 60 & Sucrose & 437 & 42.22 \\
\hline 61 & Turanose & 147 & 42.25 \\
\hline 62 & Gulose & 204 & 42.67 \\
\hline 63 & Cellobiose & 204 & 43.45 \\
\hline 64 & Maltose & 204 & 43.59 \\
\hline 65 & Mannonic acid & 217 & 43.85 \\
\hline 66 & Lyxopyranoside & 204 & 44.45 \\
\hline 67 & Trehalose & 217 & 44.59 \\
\hline 68 & Glucopyranuronic acid & 105 & 46.25 \\
\hline 69 & Galactinol & 204 & 46.99 \\
\hline 70 & Gentiobiose & 204 & 48.91 \\
\hline 71 & Sitosterol & 129 & 51.71 \\
\hline 72 & Glucopyranoside & 217 & 52.86 \\
\hline
\end{tabular}

List of 79 identified metabolites and associated $\mathrm{m} / \mathrm{z}$ scores (mass to charge ratios) and retention times in minutes (RT).

totals being $71 \%$ of control conditions, and untreated plants' organic acid totals being $77 \%$ of untreated plants under control conditions. Total sugar metabolite contents increased $37 \%$ in untreated plant during heat stress, but were not significantly changed in ASM treated plants. Since ASM treated plants had higher sugar content under non-stress control conditions, the increase in untreated plants resulted in no significant differences in total sugar content between ASM and untreated plants during heat stress. During drought stress, total amino acid content increased in both ASM treated (175\%) and untreated plants (281\%) compared to control conditions, but to a significantly greater degree in untreated plants. Organic acid totals declined during drought stress but to a significantly greater degree in ASM treated plants (50\% of controls), compared to untreated plants (67\% of controls). Total sugar content significantly increased in ASM treated and untreated plant during drought stress, by 14 and 55\%, respectively. However, there were no significant differences in total sugar content between two treatments during drought.

Under heat stress conditions 46 metabolites where significantly altered out of the 72 identified metabolites when comparing ASM to untreated plants. This included 15 amino acids, of which 8 had significant increases and 7 had decreases when compared to untreated plants (Table 2). Amino acids with higher contents in ASM treated plants were aspartic acid, glutamic acid, glutamine, glycine, isoleucine, lysine, serine, and threonine; lower content amino acids were alanine, aminomalonic acid, asparagine, GABA, histidine, proline, and tryptophan. A total of 13 organic acids were found to have differential accumulation with 6 having higher content and 7 having lower content compared to untreated plants at 54 days heat stress. Organic acids with greater accumulations 


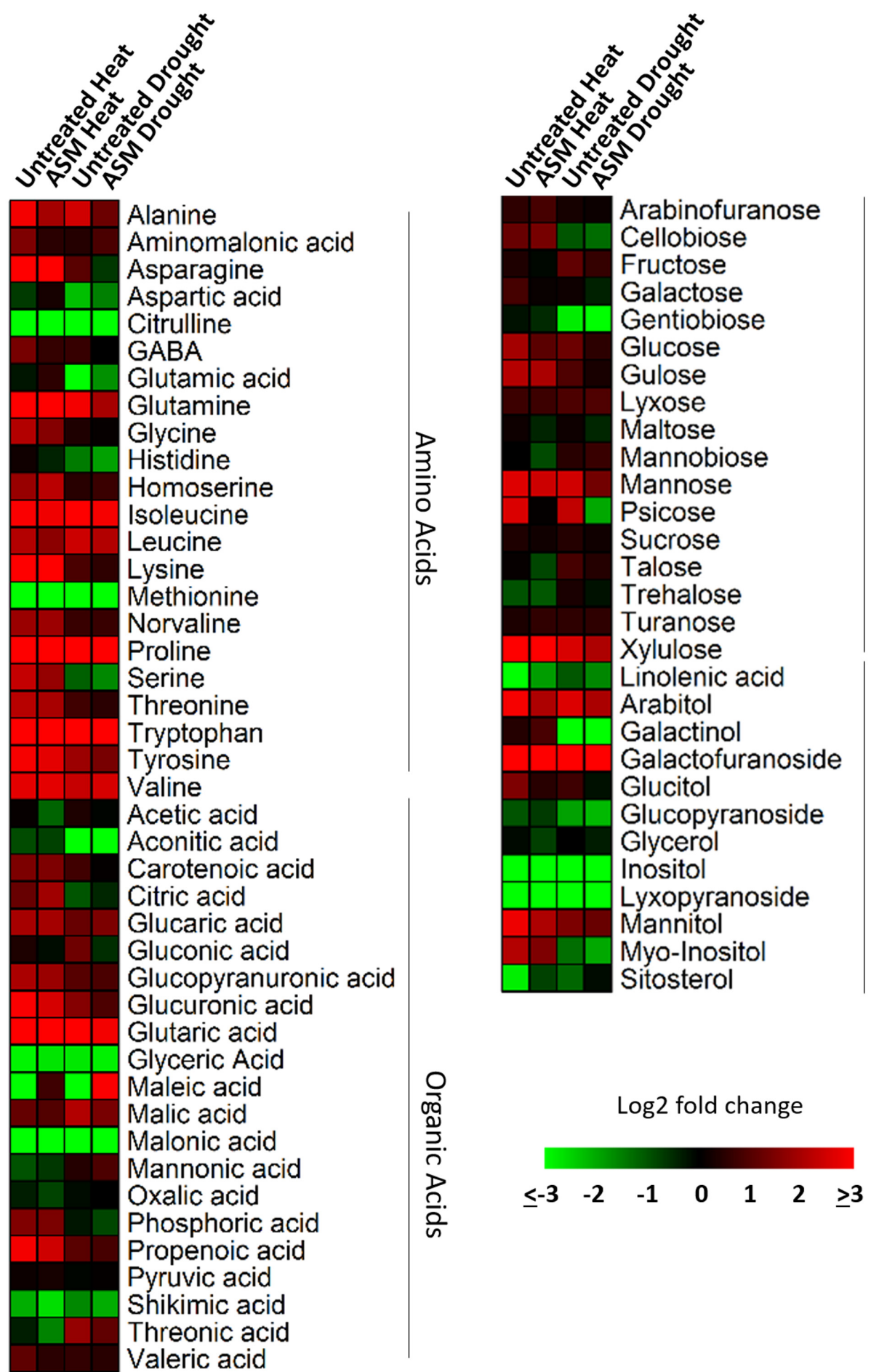

FIGURE 3 | Heat map showing fold changes for 72 identified metabolites in plants exposed to 56 days heat stress or 14 days drought stress and treated with ASM and untreated controls. Fold changes are made in comparison to non-stress condition plants with red representing up-regulation and green representing down-regulation.

included aconitic acid, carotenoic acid, citric acid, gluconic acid, malic acid, and phosphoric acid; organic acids with lower accumulations in ASM treated plants included acetic acid, glucaric acid, oxalic acid, propenoic acid, pyruvic acid, threonic acid, and valeric acid. Metabolite analysis identified 8 sugars that had significant differences, with 3 being higher and 5 being 


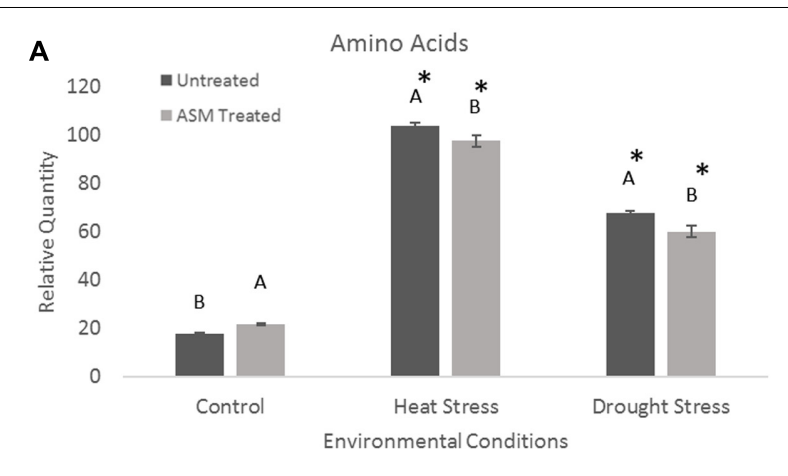

B
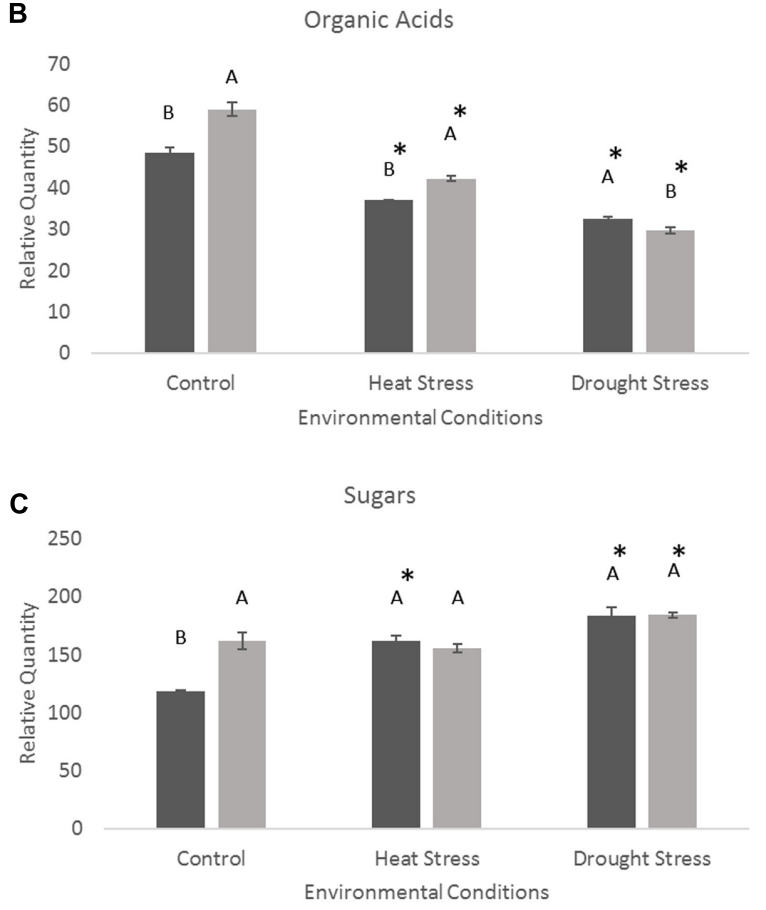

FIGURE 4 | Total relative contents for the major metabolite groups of (A) amino acids, (B) organic acids, and (C) sugars when treated with ASM or untreated and exposed to non-stress control, heat stress, or drought stress conditions. Bars represent standard error, letters are LSD groupings, with different letters being significant at $p \leq 0.05$ for treatments in a given environment (control, heat, or drought), while an asterisks $\left(^{*}\right)$ indicates a significant difference for a given treatment when compared to non-stress control conditions.

lower, as well as 10 sugar alcohols and other metabolites in which 5 were increased and 5 were decreased in ASM treated compared to untreated plant during heat stress. Sugars that had higher content in ASM treated plants during heat stress included arabinofuranose, gentiobiose, and gulose; sugars that were significantly lower in content included fructose, galactose, glucose, mannobiose, and talose. Other metabolites which were differentially accumulated include galactinol, galactofuranoside, glucopyranoside, linolenic acid, and sitosterol which had increased accumulations; while arabitol, glucitol, glycerol, inositol, and mannitol had decreased accumulations when comparing ASM treated to untreated plants during heat stress. PCA analysis results found component 1 accounted for $66.1 \%$ of the variance and component 2 accounted for $11.2 \%$ (Figure 5). ASM treated and untreated groups are distrinctly separated on component 1 , metabolites with high loading factors (top 15\%) for component 1 included aspartic acid, sitosterol, linolenic acid, fructose, glutamic acid, and citric acid.

Under drought stress conditions 24 metabolites were significantly different between ASM and untreated plants. Of the 9 amino acids found to be significantly different, 5 had higher content and 4 had lower content under drought when compared to untreated plants (Table 2). Amino acids with higher content were aminomalonic acid, aspartic acid, glutamic acid, glycine, and valine; amino acids with lower content were alanine, GABA, proline, and tryptophan. Out of 8 differentially accumulated organic acids, 3 had higher content, aconitic acid, mannonic acid, and valeric acid, while 5, carotenoic acid, gluconic acid, maleic acid, malic acid, and threonic acid, had lower content in ASM treated plants during drought when compared to untreated plants. Also during drought 4 sugars and 3 sugar alcohols and other metabolites showed significant differences with 1 sugar having higher content and 3 having lower content, and 1 other metabolite having higher content and 2 having lower content when comparing ASM treated to untreated plants at 14 days drought stress. Sugars with greater accumulations in ASM treated compared to untreated plants during drought included mannobiose, while lower accumulations were found with gulose, mannose, and psicose. Additional the metabolite sitosterol had higher accumulation, while inositol and lyxopyranoside had lower accumulation with ASM treatment during drought. PCA analysis results found component 1 accounted for $55.0 \%$ of the variance and component 2 accounted for 15.1\% (Figure 5) during drought stress. ASM treated and untreated groups are separated along component. Metabolites with high loading (top 15\%) factors for component 1 included inositol, mannose, malic acid, alanine, citric acid, asparagine, and gluconic acid.

Acibenzolar-S-methyl treatment cause significant changes in metabolites levels compared to untreated planted during both heat and drought stress treatments, although these changes were not always common between the two stresses (Figure 6). Pathway analysis identified 18 metabolic pathways that were significant enriched using Holm's adjusted $p$-value when comparing ASM treated and untreated plants under heat stress. While under drought stress conditions, 11 pathways were found to be significantly altered when comparing ASM treated and untreated plants. A total of nine pathways were commonly identified in both stresses and include alanine, aspartate and glutamate metabolism, glyoxylate and dicarboxylate metabolism, aminoacyl-tRNA biosynthesis, arginine and proline metabolism, citrate cycle (TCA cycle), carbon fixation in photosynthetic organisms, beta-alanine metabolism, nicotinate and nicotinamide metabolism, and porphyrin and chlorophyll metabolism. Additional pathways affected by ASM treatment during abiotic stress include glycine, serine, and threonine metabolism during drought, and glycerolipid metabolism, nitrogen metabolism, and glycolysis and gluconeogenesis during 


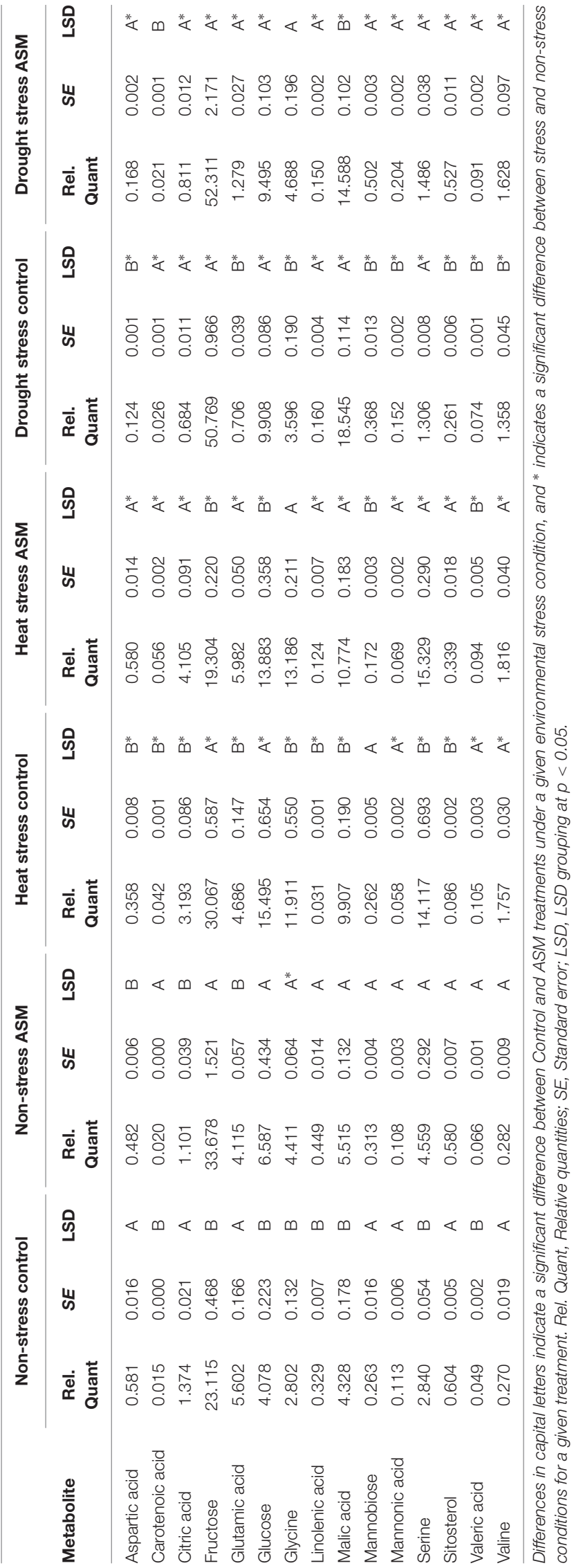

heat stress. Many of these pathways are interrelated and may result in widespread changes in plant metabolism.

\section{DISCUSSION}

Both abiotic stresses of heat or drought resulted in damage to plants over the course of the 54-days heat stress period, or 14-days drought period. However, plants which received ASM treatment had increased stress tolerance as demonstrated by lesser declines in overall visual $\mathrm{TQ}$, leaf hydration status as measured by RWC, and CHL compared to untreated plants. These three measurements of TQ, RWC, and CHL are frequently used to assess abiotic stress tolerance and have previously been shown to decline in turfgrasses as abiotic stress damages accumulate, with more tolerant cultivars maintaining high levels of these parameters than sensitive cultivars (Jespersen et al., 2013). The physiological analysis demonstrates that treatment with ASM was effective in improving creeping bentgrass tolerance to both drought and heat stress.

The ability of ASM to prime a plant's defense mechanisms to protect against disease has been widely documented (LatundeDada and Lucas, 2001; Maxson-Stein et al., 2002; Soylu et al., 2003; Beckers and Conrath, 2007), but how treatment with ASM may enhance abiotic stress tolerance has not been thoroughly studied. Plant defenses primed via ASM application induces signaling in the salicylic acid pathway, which has previously been shown to influence abiotic stress tolerance (Singh and Usha, 2003; Larkindale and Huang, 2005; Czovek et al., 2006). Plants treated with ASM have increased activities of anti-oxidant enzymes such as catalase and superoxide dismutase (Soylu et al., 2003; Deepak et al., 2006) which also have increased activity with application of salicylic acid (He et al., 2003) as an important factor influencing the damage caused by reactive oxygen species during stress events. The remaining discussion will focus on whether the positive effects of ASM on heat or drought tolerance in creeping bentgrass were associated with alteration of proteins and metabolites.

\section{ASM-Responsive Proteins and Metabolites Related to Heat Tolerance}

Induction of stress-protective proteins or energy-related proteins are critically important plant adaption to heat stress (Wahid et al., 2007). The proteins ATP synthase, HSP-20, PR-3, and Rubisco were all found via western blotting to have significantly higher accumulations in ASM treated plants compared to untreated plants during heat stress conditions. ATP synthase and Rubisco are both important proteins involved in energy metabolism that have previously been shown to be differentially accumulated during heat stress in bentgrasses (Xu and Huang, 2010; Jespersen and Huang, 2015). Maintaining these proteins may allow the plant to continue to generate energy via photosynthesis and utilize energy for stress defense and repair mechanisms, as carbon starvation is a common occurrence during prolonged heat stress (Wahid et al., 2007). HSPs, including HSP-20, are important chaperones which can refold proteins damages by heat stress and have been found to have higher accumulations in more 

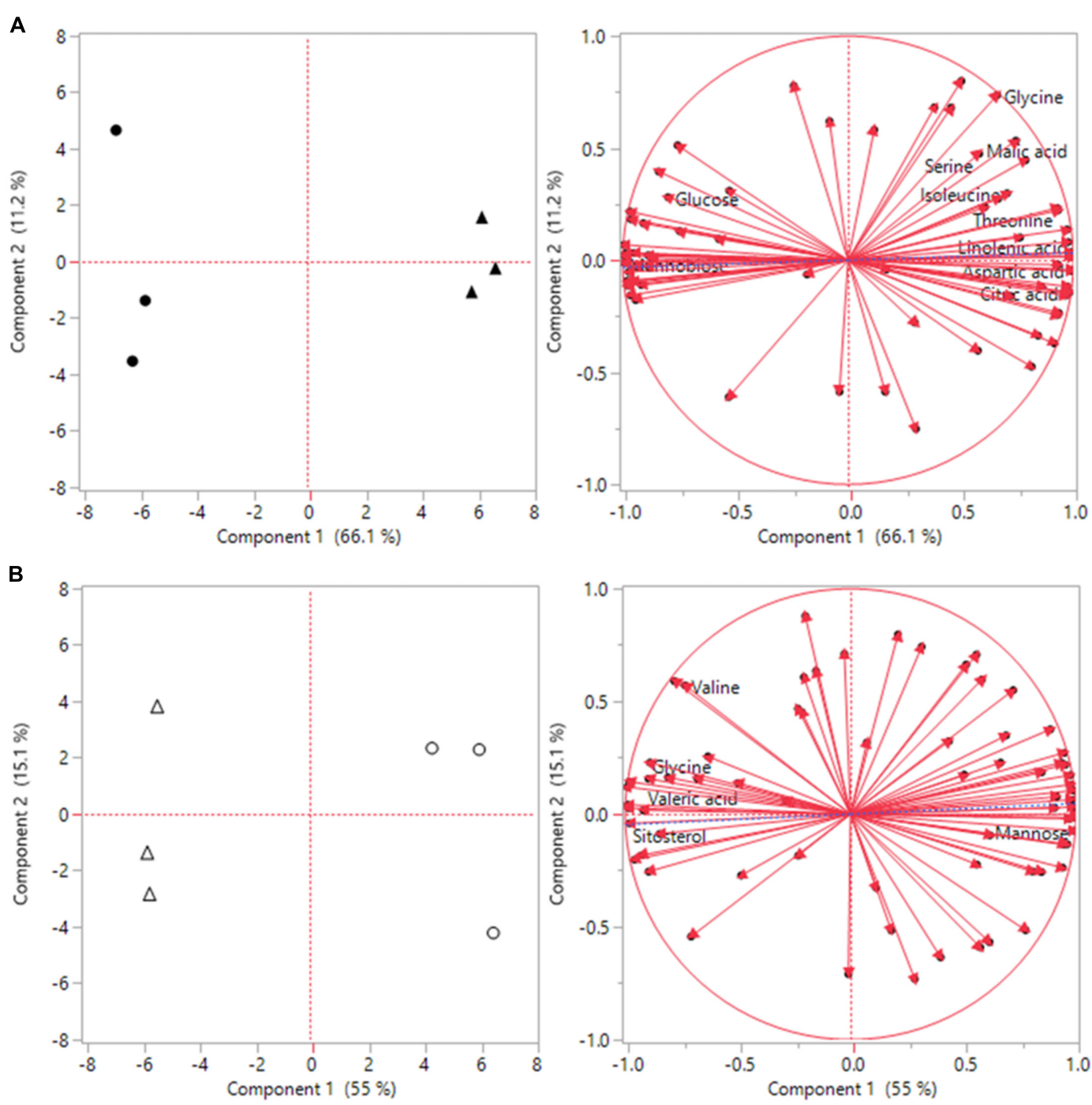

FIGURE 5 | Principle component analysis (PCA) score plots and loading plots for the first two components for (A) heat, and (B) drought stress conditions. Solid black circles represent untreated plants during heat stress, black triangles represent ASM treated plants during heat stress. White circles represent untreated plants during drought stress, and white triangles represent ASM treated plants under drought stress.

heat tolerance turfgrasses (Xu et al., 2011). The higher levels of HSP-20 in ASM treated plants may indicate a greater stress response responsible for stabilizing protein metabolism during high temperature events. Although PR-3, a chitinase, has not been implicated in abiotic stress tolerance it is an important pathogen defense protein which has been demonstrated to be activated by salicylic acid signaling and likewise by applications of ASM (Mandal et al., 2008). This may indicate that some of the pathways being activated during heat stress are commonly activated during other challenges to the plant as well.

Amino acids are important building blocks that feed into many metabolic processes and are involved in nitrogen metabolism, protein synthesis, energy relations and signaling functions (Staswick and Tiryaki, 2004; Meister, 2012). ASM treatment resulted in significantly increased accumulations of the amino acids aspartic acid, glutamic acid, glutamine, glycine, isoleucine, lysine, serine, and threonine during heat stress compared to untreated plants. Increased accumulations of the amino acids aspartic acid, glutamic acid, glycine, and serine have previously been associated with increased levels of stress tolerance in turfgrasses (Jespersen et al., 2015; Li et al., 2016). The higher accumulation of these amino acids in ASM treated plants may be part of major shifts in metabolism and activation of defense pathways. Several of these amino acids including aspartic acid, isoleucine, and threonine can act as major precursors to other amino acids and metabolites which may represent a shift in metabolism in response to stress (Azevedo et al., 2006; Joshi et al., 2010), as preferential accumulation of specific amino acids is a documented response to heat stress as plants respond to elevated temperatures (Mayer et al., 1990). Glutamic acid is an important precursor to chlorophyll biosynthesis (Forde and Lea, 2007). Elevated levels of glutamic acid is a potentially a factor 

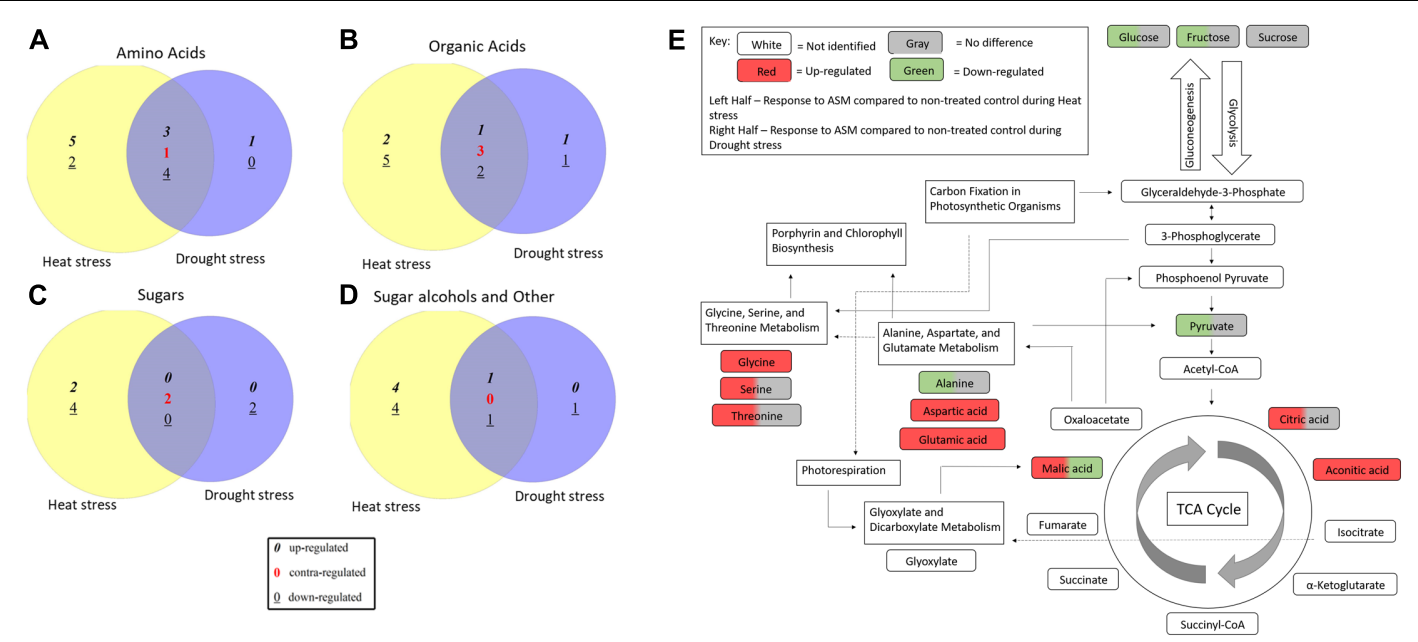

FIGURE 6 | Venn diagrams comparing (A) amino acids, (B) organic acids, (C) sugars, and (D) sugar alcohols and other metabolites significantly altered by ASM treatment compared to untreated plants under non-stress, heat, and drought stress conditions. (E) Visualization of metabolic pathways significantly altered during heat or drought stress when treated with ASM and relationships between these pathways based on enrichment analysis with Metaboanalyst and KEGG maps.

contributing to higher chlorophyll levels observed during heat stress in ASM treated plants by helping to maintain chlorophyll synthesis. The amino acid glycine can function as a compatible solute to help project the cell during stress events (Yancey et al., 1982). Furthermore, glycine is involved in the synthesis of glutathione, which is an important component of anti-oxidant metabolism (Noctor et al., 1997). Elevated levels of glycine may help ASM treated plants undergo osmotic adjustment and enhance anti-oxidant metabolism to protect against heat related damages. The activation of anti-oxidant pathways has previously been shown to be an effect of ASM treatment in plants, enhancing defense pathways (Brisset et al., 2000; Kuźniak et al., 2014). During heat stress Rubisco increasingly binds to oxygen instead of carbon dioxide in a process known as photorespiration (Wingler et al., 2000). Both glycine and serine are involved in the photorespiritory cycle which has been associated with improved stress tolerance (Moreno et al., 2005). Higher levels of glycine and serine found in ASM treated plants may be an important aspect of regulating photorespiration during heat stress to maintain an active photosynthetic system.

Organic acids have many important metabolic functions including being intermediates in the citric acid cycle, as intermediates in nitrogen metabolism, involvement in redox balance, and can be accumulated to act as compatible solutes (Sweetlove et al., 2010). Organic acids have previously been shown to be responsive to heat stress in a number of species, including in model species such as Arabidopsis thaliana and in turf species such as A. stolonifera and Festuca arundinacea (Kaplan et al., 2004; Yu et al., 2012; Xu et al., 2013). The metabolites aconitic acid, carotenoic acid, citric acid, gluconic acid, malic acid, and phosphoric acid had significantly greater accumulations in ASM treated plants than untreated plants during heat stress, and may help explain the different levels of heat tolerance seen in the two treatments. Carotenoic acids and carotenoids have been widely implicated in stress tolerance mechanisms by acting to help absorb excess energy and prevent the creation of ROS while helping maintain thylakoid integrity (Havaux, 1998). Higher accumulations of carotenoic acids in ASM treated plants may aid preventing damage to photosynthetic machinery during heat stress. Citric acid and malic aid are two of the major intermediates of the citric acid cycle to produce energy via respiration (Benkeblia et al., 2007). Heat stress typical increases respiration rates leading to an eventual decline in substrates available for energy-related reactions such as the intermediates in the citric acid cycle (Wahid et al., 2007). Elevated levels of citric acid and malic acid may indicate that ASM treated plants have higher respiratory activity to help maintain repair and defense mechanisms during prolonged heat stress. The increase accumulation of citric acid or malic acid in response to heat stress has been proposed as an important metabolic change for enhanced tolerance in a number of other metabolomics studies (Kaplan et al., 2004; Du et al., 2011; Yu et al., 2012; Jespersen et al., 2015; Li et al., 2016).

Although many less abundant sugars were increased by heat stress in both ASM and untreated plants, relatively few had significantly greater levels in ASM treated plants compared to untreated plants with the exception of the sugars arabinofuranose, gentiobiose, and gulose. Many of these sugars have the ability to act as compatible solutes to help stabilize the cell during stress events (Wang and Stutte, 1992). Other major monosaccharides such as glucose and fructose had lower concentrations in ASM treated plants than untreated plants during heat stress which may be due to changes in glycolysis and respiration rates. This shift in carbohydrate metabolism may help drive the defense and repair mechanisms needed for enhanced heat tolerance. Another metabolite which was differentially regulated between ASM and untreated plants was linolenic acid which decreased to a lower level in untreated plants during heat stress. Linolenic acid is a fatty acid which is an 
important membrane component, particularly in the thylakoid where it is a major target of oxidative damage (Shi et al., 2006). Greater levels of linolenic acid may represent less damage to chloroplast membranes from sustained ROS attack and increased heat tolerance.

\section{ASM-Responsive Proteins and Metabolites Associated with Drought Tolerance}

Dehydrins are a family of proteins involved in stabilizing cells during water stress and have been demonstrated to have increased expression in Triticum aestivum and Hordeum vulgare during drought stress (Rampino et al., 2006; Tommasini et al., 2008). Dehydrin, of the measured proteins, was the only one which ASM increased during drought. Dehydrins higher accumulations in ASM treated plants under drought conditions may improve drought tolerance, as dehydrins have previously been implicated in drought tolerance in turfgrasses based on increased expression levels in F. arundinacea and Lolium perenne (Volaire et al., 1998; Jiang and Huang, 2002).

Several amino acids had higher content during drought stress when treated with ASM compared to untreated plants which included aminomalonic acid, aspartic acid, glutamic acid, glycine, and valine. Glycine, in addition to being a proteogenic amino acid is also an important precursor to a number of important secondary metabolites including porphyrins, the compatible solute glycine betaine, and the anti-oxidant glutathione (Mok and Mok, 1994; Rivero et al., 2009). Increased glycine concentrations in response to drought have been previously found in transgenic creeping bentgrasses which demonstrated improved drought tolerance (Merewitz et al., 2011). Increased glycine concentrations induced by ASM may represent a greater activation of defense pathways imparting drought tolerance involving anti-oxidant defenses and the accumulation of protective compounds. Another metabolite that had higher levels in ASM treated plants compared to untreated plants which may contribute to drought tolerance was the hydrophobic amino acid valine. Valine was previously demonstrated to have increased accumulations in T. aestivum, Eucalyptus spp., and A. thaliana in response to drought stress as a potential defense mechanism (Rizhsky et al., 2004; Bowne et al., 2012; Warren et al., 2012). Aspartic acid was also found to experience a differential response to drought stress between ASM and untreated plants with aspartic acid decreasing to a lower level in untreated plants during drought. Maintaining aspartic acid may help ASM treated plants induce drought tolerance since aspartic acid is another proteogenic amino acid which has been found to be responsive to drought stress and, as previously mentioned, aspartic acid is a precursor to many other amino acids and may play important roles in shifting plant metabolism to cope with water stress (Good and Zaplachinski, 1994; Rai, 2002; Azevedo et al., 2006).

A number of organic acids were also found to have higher accumulations during drought stress in ASM treated plants and included aconitic acid, mannonic acid, and valeric acid.
Mannonic acid feeds into glucuronate metabolism which is involved in glycolysis (Wichelecki et al., 2014). Valeric acid is involved in fatty acid metabolism and the formation of precursors to the citric acid cycle (Stumpf and Barber, 1956). Although it is unclear how these metabolites may specifically influence cellular metabolism, it is known that changes in respiration can be a major factor during drought (Flexas et al., 2006). The change in accumulation of organic acids represents a shift in energy metabolism and related metabolites which, as previously discussed, may be an important factor in drought tolerance a promoted by ASM treatment.

A number of sugars increased in response to drought stress, however, only mannobiose was higher in ASM treated compared to untreated plants. Mannobiose is a disaccharide consisting of two mannose molecules. Mannose was found to be upregulated during drought in this and other metabolomic studies looking at drought stress (Du et al., 2012; Li et al., 2016) which may indicate the importance of mannose and related sugars in providing drought tolerance. The hydrolysis of more complex carbohydrates can result in increased levels of sugars in response to drought stress (Spollen and Nelson, 1994; Chaves et al., 2009) which may be a major aspect of osmotic adjustment, an important drought tolerance mechanism used to increase solute potential in the cell (Bray, 1997). Additionally ASM treated plants maintained greater levels of sitosterol compared to untreated plants during drought. Phytosterols, including sitosterols, are important membrane components which have been implicated in drought tolerance (Quartacci et al., 2002; Kumar et al., 2015). Maintaining sitosterol may be an important factor regulating membrane integrity and associated signaling pathways associated for drought tolerance.

In summary, while ASM has widely been studied in the context of promoting pathogen defense, relatively less is understood how it can prime plant systems to defend against abiotic stresses. This study demonstrated that exogenous application of ASM lead to improved heat or drought tolerance in creeping bentgrass. These heightened levels of tolerance were supported by physiological differences and also differences in the accumulation of key proteins. Metabolomics further delved into the metabolic differences between ASM and untreated plants during heat or drought. The differential accumulation of key metabolites such as amino acids, organic acids, and sugars indicate a change in metabolism which may increase abiotic stress tolerance through such mechanisms as improved energy relations, the accumulation of compatible solutes for osmotic adjustment and the stabilization of cellular constituents as well as metabolites needed for the production of important secondary metabolites involved in anti-oxidant metabolism or other stress defense mechanisms. ASM treatment resulted in distinct changes in the pattern of metabolite levels as seen with multivariate PCA analysis. A number of metabolic pathways were significant altered in both heat or drought stress conditions by treatment with ASM, including the citric acid cycle or glyoxylate metabolic pathways. However, a number of metabolite changes were unique to each stress, demonstrating the complex interaction between abiotic stresses and change to plant metabolism. Future research will look into the genetic and signaling pathways involved in the 
activation of these defense systems to better understand their mechanisms and how to best implement these compounds to battle abiotic stresses.

\section{AUTHOR CONTRIBUTIONS}

DJ performed experiments, analyzed data and wrote the manuscript. JY performed GC/MS experiments and data analysis. $\mathrm{BH}$ conceived and designed the experiments and wrote the manuscript.

\section{REFERENCES}

Alcázar, R., Altabella, T., Marco, F., Cortolotti, C., Reymond, M., Koncz, C., et al. (2010). Polyamines: molecules with regulatory functions in plant abiotic stress tolerance. Planta 231, 1237-1249. doi: 10.1007/s00425-010-1130-0

Arbona, V., Mazi, M., Ollas, C. D., and Gómez-Cadenas, A. (2013). Metabolomics as a tool to investigate abiotic stress tolerance in plants. Int. J. Mol. Sci. 14, 4885-4911. doi: 10.3390/ijms14034885

Arnon, D. I. (1949). Copper enzymes in isolated chloroplasts. Polyphenoloxidase in Beta vulgaris. Plant Physiol. 24, 1-15. doi: 10.1104/pp.24.1.1

Azevedo, R. A., Lancien, M., and Lea, P. J. (2006). The aspartic acid metabolic pathway, an exciting and essential pathway in plants. Amino Acids 30, 143-162. doi: 10.1007/s00726-005-0245-2

Baldoni, E., Mattana, M., Locatelli, F., Consonni, R., Cagliani, L. R., Picchi, V., et al. (2013). Analysis of transcript and metabolite levels in Italian rice (Oryza sativa L.) cultivars subjected to osmotic stress or benzothiadiazole treatment. Plant Physiol. Biochem. 70, 492-503. doi: 10.1016/j.plaphy.2013. 06.016

Barilli, E., Rubiales, D., and Castillejo, M. Á (2012). Comparative proteomic analysis of BTH and BABA-induced resistance in pea (Pisum sativum) toward infection with pea rust (Uromyces pisi). J. Proteomics 75, 5189-5205. doi: 10.1016/j.jprot.2012.06.033

Barrs, H. D. (1962). A re-examination of the relative turgidity techniques for estimating water deficits in leaves. Aust. J. Biol. Sci. 15, 413-428. doi: 10.1071/ BI9620413

Basra, A. S. (2000). Plant Growth Regulators in Agriculture and Horticulture: Their Role and Commercial Uses. Binghamton, NY: Food Products Press.

Beckers, G. J., and Conrath, U. (2007). Priming for stress resistance: from the lab to the field. Curr. Opin. Plant Biol. 10, 425-431. doi: 10.1016/j.pbi.2007.06.002

Benkeblia, N., Shinano, T., and Osaki, M. (2007). Metabolite profiling and assessment of metabolome compartmentation of soybean leaves using non-aqueous fractionation and GC-MS analysis. Metabolomics 3, 297-305. doi: 10.1007/s11306-007-0078-y

Bowne, J. B., Erwin, T. A., Juttner, J., Schnurbusch, S., Langridge, P., Bacic, A., et al. (2012). Drought responses of leaf tissues from wheat cultivars of differing drought tolerance at the metabolite level. Mol. Plant 5, 418-429. doi: 10.1093/ $\mathrm{mp} / \mathrm{ssr} 114$

Bradford, M. M. (1976). A rapid and sensitive method for the quantification of microgram quantities protein using the principle of protein-dye binding. Ann. Biochem. 72, 248-254. doi: 10.1016/0003-2697(76)90527-3

Bray, E. A. (1997). Plant responses to water deficit. Trends Plant Sci. 2, 48-54. doi: 10.1016/S1360-1385(97)82562-9

Brisset, M.-N., Cesbron, S., Thomson, S. V., and Paulin, J.-P. (2000). AcibenzolarS-methyl induces the accumulation of defense-related enzymes in apple and protects from fire blight. Eur. J. Plant Pathol. 106, 529-536. doi: 10.1023/A: 1008728119087

Burketová, L., Šindelářová, M., and Šindeláŕ, L. (1999). Benzothiadiazole as an inducer of $\beta$-1,3-glucanase and chitinase isozymes in sugar beet. Biol. Plant. 42, 279-287. doi: 10.1023/A:1002172921426

Cai, H., Chen, H., Yi, T., Daimon, C. M., Boyle, J. P., Peers, C., et al. (2013). VennPlex- A novel venn diagram program for comparing and visualizing datasets with differentially regulated datapoints. PLOS ONE 8:e53388. doi: 10.1371 /journal.pone.0053388

\section{ACKNOWLEDGMENT}

Thanks go to New Jersey Agricultural Experiment Station for supporting this project.

\section{SUPPLEMENTARY MATERIAL}

The Supplementary Material for this article can be found online at: http://journal.frontiersin.org/article/10.3389/fpls.2017.01224/ full\#supplementary-material

Cao, J., and Jiang, W. (2006). Induction of resistance in Yali pear (Pyrus bretschneideri Rehd.) fruit against postharvest diseases by acibenzolar-S-methyl sprays on trees during fruit growth. Sci. Horticult. 110, 181-186. doi: 10.1016/j. scienta.2006.07.002

Cao, J., Jiang, W., and He, H. (2005). Induced resistance in yali pear (Pyrus bretschneideri Rehd.) fruit against infection by penicillium expansum by postharvest infiltration of acibenzolar-S-methyl. J. Phytopathol. 153, 640-646. doi: 10.1111/j.1439-0434.2005.01031.x

Cavalcanti, F. R., Resende, M. L. V., Lima, J. P. M. S., Silveira, J. A. G., and Oliveira, J. T. A. (2006). Activities of antioxidant enzymes and photosynthetic responses in tomato pre-treated by plant activators and inoculated by Xanthomonas vesicatoria. Physiol. Mol. Plant Pathol. 68, 198-208. doi: 10.1016/j.pmpp.2006. 11.001

Chaves, M. M., Flexas, J., and Pinheiro, C. (2009). Photosynthesis under drought and salt stress: regulation mechanisms from whole plant to cell. Ann. Bot. 103, 551-560. doi: 10.1093/aob/mcn125

Chen, Z., Chen, B., Guo, Q., Shi, L., He, M., Qin, Z., et al. (2015). A time-course proteomic analysis of rice triggered by plant activator BTH. J. Plant Growth Regul. 34, 392-409. doi: 10.1007/s00344-015-9476-y

Czovek, P., Király, I., Páldi, E., Molnár, I., and Gáspár, L. (2006). Comparative analysis of stress tolerance in Aegilops accessions and Triticum wheat varieties to detect different drought tolerance strategies. Acta Agron. Hung. 54, 49-60. doi: 10.1556/AAgr.54.2006.1.5

Dao, T. T., Puig, R. C., Kim, H. K., Erkelens, C., Lefeber, A. W. M., Linthorst, H. J. M., et al. (2009). Effect of benzothiadiazole on the metabolome of Arabidopsis thaliana. Plant Physiol. Biochem. 47, 146-152. doi: 10.1016/j.plaphy. 2008.10.001

Deepak, S. A., Ishii, H., and Park, P. (2006). Acibenzolar-S-methyl primes cell wall strengthening genes and reactive oxygen species forming/scavenging enzymes in cucumber after fungal pathogen attack. Physiol. Mol. Plant Pathol. 69, 52-61. doi: 10.1016/j.pmpp.2006.12.006

Deepak, S., Niranjan-Raj, S., Shailasree, S., Kini, R. K., Boland, W., Shetty, H. S., et al. (2007). Induction of resistance against downy mildew pathogen in pearl millet by a synthetic jasmonate analogon. Physiol. Mol. Plant Pathol. 71, 96-105. doi: 10.1016/j.pmpp.2007.12.003

Du, H., Wang, Z., Yu, W., and Huang, B. (2012). Metabolic responses of hybrid bermudagrass to short-term and long-term drought stress. J. Am. Soc. Hort. Sci. 137, 411-420.

Du, H., Wang, Z., Yu, W., Liu, Y., and Huang, B. (2011). Differential metabolic responses of perennial grass Cynodon transvaalensis $\times$ Cynodon dactylon (C4) and Poa Pratensis (C3) to heat stress. Physiol. Plant. 141, 251-264. doi: 10.1111/ j.1399-3054.2010.01432.x

Durner, J., Shah, J., and Klessig, D. F. (1997). Salicylic acid and disease resistance in plants. Trends Plant Sci. 2, 266-274. doi: 10.1016/S1360-1385(97)86349-2

Feller, U., Anders, I., and Demiresvska, K. (2008). Degradation of Rubisco and other chloroplast proteins under abiotic stress. Gen. Appl. Plant Phyiol. 34, 5-18. doi: 10.1186/s12864-015-1657-3

Flexas, J., Bota, J., Galmés, J., Medrano, H., and Ribas-Carbó, M. (2006). Keeping a positive carbon balance under adverse conditions: responses of photosynthesis and respiration to water stress. Physiol. Plant. 127, 343-352. doi: 10.1111/j. 1399-3054.2006.00621.x

Forde, B. G., and Lea, P. J. (2007). Glutamate in plants: metabolism, regulation, and signalling. J. Exp. Bot. 58, 2339-2358. doi: 10.1093/jxb/erm121 
Good, A. G., and Zaplachinski, S. T. (1994). The effects of drought stress on free amino acid accumulation and protein synthesis in Brassica napus. Physiol. Plant. 90, 9-14. doi: 10.1111/j.1399-3054.1994. tb02185.x

Gross, D., and Parthier, B. (1994). Novel natural substances acting in plant growth regulation. J. Plant Growth Regul. 13, 93. doi: 10.1007/bf00210953

Gunel, A., Asbahi, A., Ozgazi, N., and Akkaya, M. S. (2012). Identification of differentially expressed proteins in wheat after benzothiadiazole treatment. J. Plant Dis. Prot. 119, 182-190. doi: 10.1007/BF03356440

Handa, S., Bressan, R. A., Handa, A. K., Carpita, N. C., and Hasegawa, P. M. (1983). Solutes contributing to osmotic adjustment in cultured plant cells adapted to water stress. Plant Physiol. 73, 834-843. doi: 10.1104/pp.73. 3.834

Hanin, M., Brini, F., Ebel, C., Toda, Y., Takeda, S., and Masmoudi, K. (2011). Plant dehydrins and stress tolerance. Plant Signal. Behav. 6, 1503-1509. doi: $10.4161 / p s b .6 .10 .17088$

Havaux, M. (1998). Carotenoids as membrane stabilizers in chloroplasts. Trends Plant Sci. 3, 147-151. doi: 10.1016/S1360-1385(98)01200-X

He, Y., Lie, Y., Cao, W., Huai, M., Xu, B., and Huang, B. (2003). Effects of salicylic acid on heat tolerance associated with antioxidant metabolism in kentucky bluegrass. Crop Sci. 45, 988-995. doi: 10.2135/cropsci2003.0678

Hiscox, J. D., and Israelstam, G. F. (1979). A method for the extraction of chlorophyll from leaf tissue without maceration. Can. J. Bot. 57, 1332-1334. doi: $10.1139 / \mathrm{b} 79-163$

Hoagland, C. R., and Arnon, D. I. (1950). The solution culture method for growing plants without soil. Calif. Agr. Expt. Circ. 347, 1-32.

Horváth, E., Szalai, G., and Janda, T. (2007). Induction of abiotic stress tolerance by salicylic acid signaling. J. Plant Growth Regul. 26, 290-300. doi: 10.1007/s00344007-9017-4

Iriti, M., Rossoni, M., Borgo, M., Ferrara, L., and Faoro, F. (2005). Induction of resistance to gray mold with benzothiadiazole modifies amino acid profile and increases proanthocyanidins in grape: primary versus secondary metabolism. J. Agric. Food Chem. 53, 9133-9139. doi: 10.1021/jf050853g

Janda, T., Szalai, G., Tari, I., and Paldi, E. (1999). Hydroponic treatment with salicylic acid decreases the effects of chilling injury in maize (Zea mays L.) plants. Planta 208, 175-180. doi: 10.1007/s004250050547

Jespersen, D., and Huang, B. (2015). Proteins associated with heat-induced leaf senescence in creeping bentgrass as affected by foliar application of nitrogen, cytokinins, and an ethylene inhibitor. Proteomics 15, 798-812. doi: 10.1002/ pmic. 201400393

Jespersen, D., and Huang, B. (2016). Effects of trinexapac-ethyl and daconil action (acibenzolar-S-methyl and chlorothalonil) on heat and drought tolerance of creeping bentgrass. Crop Sci. doi: 10.2135/cropsci2016.05.0377

Jespersen, D., Meyer, W. A., and Huang, B. (2013). Physiological traits and genetic variations associated with drought and heat tolerance in creeping bentgrass. Int Turfgrass Soc. Res. J. 12, 459-464.

Jespersen, D., Yu, J., and Huang, B. (2015). Metabolite responses to exogenous application of nitrogen, cytokinin, and ethylene inhibitors in relation to heat-induced senescence in creeping bentgrass. PLOS ONE 10:e0123744. doi: 10.1371/journal.pone.0123744

Jiang, Y., and Huang, B. (2002). Protein alterations in tall fescue in response to drought stress and abscisic acid. Crop Sci. 42, 202-207. doi: 10.2135/ cropsci2002.0202

Joshi, V., Joung, J. G., Fei, Z., and Jander, G. (2010). Interdependence of threonine, methionine and isoleucine metabolism in plants: accumulation and transcriptional regulation under abiotic stress. Amino Acids 39, 933-947. doi: 10.1007/s00726-010-0505-7

Kaplan, F., Kopka, J., Haskell, D. W., Zhao, W., Schiller, K. C., Gatzke, N., et al. (2004). Exploring the temperature-stress metabolome of Arabidopsis. Plant Physiol. 136, 4159-4168. doi: 10.1104/pp.104.052142

Kosová, K., Vítámvás, P., Prášil, I. T., and Renaut, J. (2011). Plant proteome changes under abiotic stress - Contribution of proteomics studies to understanding plant stress response. J. Proteomics 74, 1301-1322. doi: 10.1016/j.jprot.2011. 02.006

Krans, J. V., and Morris, K. (2007). Determining a profile of protocols and standards used in the visual field assessment of turfgrass: a survey of national turfgrass evaluation program-sponsored university scientists. Appl. Turf. Sci. 4, 1-6. doi: 10.1094/ats-2007-1130-01-tt
Kumar, M. S. S., Ali, K., Dahuja, A., and Tyagi, A. (2015). Role of phytosterols in drought stress tolerance in rice. Plant Physiol. Biochem. 96, 83-89. doi: 10.1016/j.plaphy.2015.07.014

Kuźniak, E., Głowacki, R., Chwatko, G., Kopczewski, T., Wielanek, M., Gajewska, E., et al. (2014). Involvement of ascorbate, glutathione, protein S-thiolation and salicylic acid in benzothiadiazole-inducible defence response of cucumber against Pseudomonas syringae pv lachrymans. Physiol. Mol. Plant Pathol. 86, 89-97. doi: 10.1016/j.pmpp.2014.04.004

Larkindale, J., and Huang, B. (2005). Effects of abscisic acid, salicylic acid, ethylene and hydrogen peroxide in thermotolerance and recovery for creeping bentgrass. Plant Growth Regul. 47, 17-28. doi: 10.1007/s10725-005-1536-z

Latunde-Dada, A. O., and Lucas, J. A. (2001). The plant defense activator acibenzolar-S-methyl primes cowpea seedlings for rapid induction of resistance. Physiol. Mol. Plant Pathol. 58, 199-208. doi: 10.1006/pmpp.2001. 0327

Lawton, K. A., Friedrich, L., Hunt, M., Weymann, K., Delaney, T., Kessmann, H., et al. (1996). Benzothiadiazole induces disease resistance in Arabidopsis by activation of the systemic acquired resistance signal transduction pathway. Plant J. 10, 71-82. doi: 10.1046/j.1365-313X.1996.10010071.x

Li, L., Staden, J., and Jäger, A. K. (1998). Effects of plant growth regulators on the antioxidant system in seedlings of two maize cultivars subjected to water stress. Plant Growth Regul. 23, 81-87. doi: 10.1023/A:1010774725695

Li, Z., Yu, J., Peng, Y., and Huang, B. (2016). Metabolic pathways regulated by abscisic acid, salicylic acid, and $\gamma$-aminobutyric acid in association with improved drought tolerance in creeping bentgrass (Agrostis stolonifera). Physiol. Plant. 159, 42-58. doi: 10.1111/ppl.12483

Mandal, B., Mandal, S., Csinos, A. S., Martinez, N., Culbreath, A. K., and Pappu, H. R. (2008). Biological and molecular analyses of the acibenzolar-S-methylinduced systemic acquired resistance in flue-cured tobacco against tomato spotted wilt virus. Phytopathology 98, 196-204. doi: 10.1094/PHYTO-98-20196

Maxson-Stein, K., He, S. Y., Hammerschmidt, R., and Jones, A. L. (2002). Effect of treating apple trees with acibenzolar-S-methyl on fire blight and expression of pathogenesis-related protein genes. Plant Dis. 86, 785-790. doi: 10.1094/PDIS. 2002.86.7.785

Mayer, R. R., Cherry, J. H., and Rhodes, D. (1990). Effects of heat shock on amino acid metabolism of cowpea cells. Plant Physiol. 94, 796-810. doi: 10.1104/pp.94. 2.796

Meher, H. C., Gajbhiye, V. T., Singh, G., and Chawla, G. (2015). Altered metabolomic profile of selected metabolites and improved resistance of Cicer arietinum (L.) against Meloidogyne incognita (Kofoid \& White) Chitwood following seed soaking with salicylic acid, benzothiadiazole or nicotinic acid. Acta Physiol. Plant 37, 140. doi: 10.1007/s11738-015-1888-6

Meister, A. (2012). Biochemistry of the Amino Acids. Amsterdam: Elsevier.

Merewitz, E. B., Du, H., Yu, W., Liu, Y., Gianfagna, T., and Huang, B. (2011). Elevated cytokinin content in ipt transgenic creeping bentgrass promotes drought tolerance through regulating metabolite accumulation. J. Exp. Bot. 63, 1315-1328. doi: 10.1093/jxb/err372

Mok, D. W. S., and Mok, M. C. (1994). Cytokinins: Chemistry, Activity, and Function. Salem, MA: CRC Press.

Moreno, J. I., Martín, R., and Castresana, C. (2005). Arabidopsis SHMT1, a serine hydroxymethyltransferase that functions in the photorespiratory pathway influences resistance to biotic and abiotic stress. Plant J. 41, 451-463. doi: 10.1111/j.1365-313X.2004.02311.x

Narusaka, Y., Narusaka, M., Horio, T., and Ishii, H. (1999). Comparison of local and systemic induction of acquired disease resistance in cucumber plants treated with benzothiadiazoles or salicylic acid. Plant Cell Physiol. 40, 388-395. doi: 10.1093/oxfordjournals.pcp.a029554

Noctor, G., Arisic, C. M., Jouanin, L., Valadier, H. M., Roux, Y., and Foyer, C. H. (1997). The role of glycine in determining the rate of glutathione synthesis in poplar. Possible implications for glutathione production during stress. Physiol. Plant. 100, 255-263. doi: 10.1111/j.1399-3054.1997.tb04781.x

Qiu, Y., Su, M., Liu, Y., Chen, M., Gu, J., Zhang, J., et al. (2007). Application of ethyl chloroformate derivatization for gas chromatography-mass spectrometry based metabolomic profiling. Anal. Chim. Acta 583, 277-283. doi: 10.1016/j.aca. 2006.10.025

Quartacci, M. F., Glišić, O., Stevanović, B., and Navari-Izzo, F. (2002). Plasma membrane lipids in the resurrection plant Ramonda serbica following 
dehydration and rehydration. J. Exp. Bot. 53, 2159-2166. doi: 10.1093/jxb/ erf076

Rai, V. K. (2002). Role of amino acids in plant responses to stresses. Biol. Plant. 45, 481-487. doi: 10.1023/A:1022308229759

Rampino, P., Pataleo, S., Gerardi, C., Mita, G., and Perrotta, C. (2006). Drought stress response in wheat: physiological and molecular analysis of resistant and sensitive genotypes. Plant Cell Environ. 29, 2143-2152. doi: 10.1111/j.13653040.2006.01588.x

Reddy, A. R., Chaitanya, K. V., and Vivekanandan, M. (2004). Drought-induced responses of photosynthesis and antioxidant metabolism in higher plants. J. Plant Physiol. 161, 1189-1202. doi: 10.1016/j.jplph.2004.01.013

Rivero, R. M., Shulaev, V., and Blumwald, E. (2009). Cytokinin-dependent photorespiration and the protection of photosynthesis during water deficit. Plant Physiol. 150, 1530-1540. doi: 10.1104/pp.109.139378

Rizhsky, L., Liang, H., Shuman, J., Shulaev, V., Davletova, S., and Mittler, R. (2004). When defense pathways collide. the response of Arabidopsis to a combination of drought and heat stress. Plant Physiol. 134, 1683-1696. doi: 10.1104/pp.103. 033431

Roessner, U., Wagner, C., Kopka, J., Trethewey, R. N., and Willmitzer, L. (2000). Simultaneous analysis of metabolites in potato tuber by gas chromatographymass spectrometry. Plant J. 23, 131-142. doi: 10.1046/j.1365-313x.2000.00774.x

Shekoofa, A., Rosas-Anderson, P., Carley, D. S., Sinclair, T. R., and Rufty, T. W. (2015). Limited transpiration under high vapor pressure deficits of creeping bentgrass by application of Daconil-Action. Planta 243, 421-427. doi: 10.1007/ s00425-015-2417-y

Shi, Q., Bao, Z., Zhu, Z., Ying, Q., and Qian, Q. (2006). Effects of different treatments of salicylic acid on heat tolerance, chlorophyll fluorescence, and antioxidant enzyme activity in seedlings of Cucumis sativa L. Plant Growth Regul. 48, 127-135. doi: 10.1007/s11103-015-0423-x

Singh, B., and Usha, K. (2003). Salicylic acid induced physiological and biochemical changes in wheat seedlings under water stress. Plant Growth Regul. 39, 137-141. doi: 10.1023/A:1022556103536

Soylu, E. M., Soylu, S., and Baysal, Ö. (2003). Induction of disease resistance and antioxidant enzymes by acinezolar-S-methyl against bacterial canker in tomato. J. Plant Pathol. 85, 175-181.

Spollen, W. G., and Nelson, C. J. (1994). Response of fructan to water deficit in growing leaves of tall fescue. Plant Physiol. 106, 329-336. doi: 10.1104/pp.106. 1.329

Staswick, P. E., and Tiryaki, I. (2004). The oxylipin signal jasmonic acid is activated by an enzyme that conjugates it to isoleucine in Arabidopsis. Plant Cell 16, 2117-2127. doi: 10.1105/tpc.104.023549

Stumpf, P. K., and Barber, G. A. (1956). Fat metabolism in higher plants. VII. $\beta$-oxidation of fatty acids by peanut mitochondria. Plant Physiol. 31, 304-308. doi: $10.1104 /$ pp.31.4.304

Sweetlove, L. J., Beard, K. F. M., Nunes-Nesi, A., Fernie, A. R., and Ratcliffe, R. G. (2010). Not just a circle: flux modes in the plant TCA cycle. Trends Plant Sci. 15, 462-470. doi: 10.1016/j.tplants.2010.05.006

Tezara, W., Mitchell, V. J., Driscoll, S. D., and Lawlor, D. W. (1999). Water stress inhibits plant photosynthesis by decreasing coupling factor and ATP. Nature 401, 914-917. doi: 10.1038/44842

Tommasini, L., Svensson, J. T., Rodriguez, E. M., Wahid, A., Malatrasi, M., Kato, K., et al. (2008). Dehydrin gene expression provides an indicator of low temperature and drought stress: transcriptome-based analysis of Barley (Hordeum vulgare L.). Funct. Integr. Genomics 8, 387-405. doi: 10.1007/s10142008-0081-z
Volaire, F., Thomas, H., Bertagne, N., Bourgeois, E., Gautier, M. F., and Lelièvre, F. (1998). Survival and recovery of perennial forage grasses under prolonged Mediterranean drought: II. Water status, solute accumulation, abscisic acid concentration and accumulation of dehydrin transcripts in bases of immature leaves. New Phytol. 140, 451-460. doi: 10.1093/aob/ mcv037

Wahid, A., Gelani, S., Ashraf, M., and Foolad, M. R. (2007). Heat tolerance in plants: an overview. Environ. Exp. Bot. 61, 199-223. doi: 10.1016/j.envexpbot. 2007.05.011

Wang, W., Vinocur, B., Shoseyov, O., and Altman, A. (2004). Role of plant heatshock proteins and molecular chaperones in the abiotic stress response. Trends Plant Sci. 9, 244-252. doi: 10.1016/j.tplants.2004.03.006

Wang, Z., and Stutte, G. W. (1992). The role of carbohydrates in active osmotic adjustment in apple under water stress. J. Am. Soc. Hort. Sci. 117, 816-823.

Warren, C. R., Aranda, I., and Cano, F. J. (2012). Metabolomics demonstrates divergent responses of two Eucalyptus species to water stress. Metabolomics 8, 186-200. doi: 10.1007/s11306-011-0299-y

Wichelecki, D. J., Graff, D. C., Al-Obaidi, N., Almo, S. C., and Gerlt, J. A. (2014). Identification of the in vivo function of the high-efficiency D-mannonate dehydratase in Caulobacter crescentus NA1000 from the enolase superfamily. Biochemistry 53, 4087-4089. doi: 10.1021/bi500683x

Wingler, A., Lea, P. J., Quick, W. P., and Leegood, R. C. (2000). Photorespiration: metabolic pathways and their role in stress protection. Philos. Trans. R. Soc. Lond. B Biol. Sci. 355, 1517-1529. doi: 10.1098/rstb.2000.0712

Xia, J., and Wishart, D. S. (2016). Using MetaboAnalyst 3.0 for comprehensive metabolomis data analysis. Curr. Protoc. Bioinform. 55, 1-14.

$\mathrm{Xu}, \mathrm{C}$., and Huang, B. (2010). Differential proteomic response to heat stress in thermal Agrostis scabra and heat-sensitive Agrostis stolonifera. Physiol. Plant. 139, 192-204. doi: 10.1111/j.1399-3054.2010.01357.x

$\mathrm{Xu}, \mathrm{Y}$., Du, H., and Huang, B. (2013). Identification of metabolites associated with superior heat tolerance in thermal bentgrass through metabolic profiling. Crop Sci. 53, 1626-1635. doi: 10.2135/cropsci2013.01.0045

$\mathrm{Xu}, \mathrm{Y} ., \mathrm{Zhan}, \mathrm{C}$. , and Huang, B. (2011). Heat shock proteins in association with heat tolerance in grasses. Int. J. Proteomics 2011:e529648. doi: 10.1155/2011/ 529648

Yancey, P. H., Clark, M. E., Hand, S. C., Bowlus, R. D., and Somero, G. N. (1982). Living with water stress: evolution of osmolyte systems. Science 217, 1214-1222. doi: 10.1126/science.7112124

Yu, J., Du, H., Xu, M., and Huang, B. (2012). Metabolic responses to heat stress under elevated atmospheric $\mathrm{CO} 2$ concentration in a cool-season grass species. J. Am. Soc. Hort. Sci. 137, 221-228.

Zhang, X., Ervin, E. H., and Schmidt, R. E. (2003). Plant growth regulators can enhance the recovery of Kentucky bluegrass sod from heat injury. Crop Sci. 43, 952-956. doi: 10.2135/cropsci2003.9520

Conflict of Interest Statement: The authors declare that the research was conducted in the absence of any commercial or financial relationships that could be construed as a potential conflict of interest.

Copyright (C) 2017 Jespersen, Yu and Huang. This is an open-access article distributed under the terms of the Creative Commons Attribution License (CC BY). The use, distribution or reproduction in other forums is permitted, provided the original author(s) or licensor are credited and that the original publication in this journal is cited, in accordance with accepted academic practice. No use, distribution or reproduction is permitted which does not comply with these terms. 